\title{
EXPLOTACIÓN DE LA SAL, VÍAS DE COMUNICACIÓN Y TERRITORIO DURANTE LA EDAD DEL HIERRO EN EL ENTORNO DEL RÍO CABRIEL
}

\author{
SALT EXPLOITATION, COMMUNICATION ROUTES AND TERRITORY \\ DURING THE IRON AGE AROUND THE CABRIEL RIVER VALLEY
}

\author{
DAVID QUIXAL SANTOS \\ Profesor Ayudante Doctor, Departamento de Prehistoria, Arqueología e Ha Antigua, \\ Facultad de Geografía e Historia, Universitat de València. Av. Blasco Ibáñez 28, 46010, València. \\ Correo-e: david.quixal@uv.es (D) https://orcid.org/0000-0002-7477-1292 \\ Researcher ID: https://publons.com/researcher/3872013
}

Resumen: La sal era un recurso fundamental en la economía de las sociedades antiguas y cada vez tenemos más datos sobre su aprovechamiento y explotación durante la Edad del Hierro en ámbito peninsular. La comarca de Requena-Utiel, en el interior de la provincia de Valencia, presenta la mayor abundancia de salinas continentales históricas del territorio valenciano. Por otro lado, en La Manchuela conquense se localiza la importante mina de sal de Minglanilla-La Pesquera. El hallazgo de material arqueológico ibérico en algunas de estas explotaciones sirve como punto de partida para analizar sus características y ver cómo pudieron quedar integradas en el patrón de asentamiento, así como en una densa red de caminos, veredas e intercambios comerciales entre dos territorios ibéricos situados a ambos lados del río Cabriel, los de Kelin (Caudete de las Fuentes, Valencia) e Ikalesken (Iniesta, Cuenca).

Palabras clave: Salinas continentales, minería de sal, Arqueología Ibérica, Arqueología del Paisaje, meseta de Requena-Utiel.

\begin{abstract}
Salt was an important resource in the economy of ancient societies and we have more and more data about its use and exploitation during the Iron Age in the Iberian Peninsula. The Requena-Utiel region, in the interior of the province of Valencia, has the greatest abundance of historical continental salt evaporation ponds in the Valencian territory. On the other hand, the important salt mine of Minglanilla-La Pesquera is located in La Manchuela (Cuenca). The discovery of Iberian archaeological material in some of them is a starting point to analyse their characteristics and to see how they could have been integrated into the settlement pattern. At the same time, they were part of a dense network of paths, livestock trails and trade between two Iberian territories, Kelin (Caudete de las Fuentes, Valencia) and Ikalesken (Iniesta, Cuenca), both located at two sides of the Cabriel river valley.
\end{abstract}

Key words: Salt evaporation ponds, salt mining, Iberian Archaeology, Landscape Archaeology, Requena-Utiel Plateau. 
"Por tanto, una vida civilizada no puede pasar sin sal - ¡palabra!"

(Plin. Nat. 31.88)

\section{INTRODUCCIÓN A LA HISTORIA Y ARQUEOLOGÍA DE LA SAL}

La sal o cloruro de sodio $(\mathrm{NaCl})$ ha sido un elemento fundamental a lo largo de la historia. Su uso alimenticio, condimento para salar alimentos, es el más conocido. Sin embargo, existen y han existido muchos otros, relacionados con todo tipo de actividades: usos medicinales y terapéuticos, manutención del ganado, conservación de alimentos u otras materias orgánicas, curtido de pieles y cuero, utilizaciones industriales o para deshacer el hielo (Alexianu et al. 2015). Su capacidad para preservar los alimentos le daba una importancia vital en épocas con pocas posibilidades de alargar la vida de la carne o del pescado. En este sentido, era frecuente el uso de la sal como conservante, como también lo era la utilización de hielo, nieve, miel o aceite, así como el empleo de otras técnicas como el secado o el ahumado. Era necesaria en la elaboración de múltiples derivados de la leche como la mantequilla o determinados tipos de quesos. Del mismo modo, entre los diversos usos industriales durante la Antigüedad, podemos destacar su utilización en los tintes de la ropa, en la metalurgia y en la producción cerámica. En la metalurgia servía para endurecer los metales con la técnica del temple (agua con sal) y también participaba en los procesos de copelación de la plata (Liv. 45.29.12). Aunque no tan conocido, también era utilizada en la industria alfarera, siendo una substancia beneficiosa para mezclar con la arcilla y obtener pastas más blanquecinas (Martínez Maganto 2005: 115).

Debemos diferenciar el concepto de sal, entendida como las partículas salinas, de la salmuera, que es la disolución de esas partículas en el agua, pero siempre con un grado de saturación menor que la de la sal marina (sal maritimus). Su explotación a lo largo de la historia ha sido en forma sólida como mineral (sal gema o halita) o bien disuelta en agua, tanto marina como continental (lagos, ríos o manantiales). La primera requiere de un tipo de explotación muy semejante al de la minería, ya que puede ser tanto superficial como subterránea. Por ello encontramos una fuerte heterogeneidad en las técnicas y métodos de extracción y aprovechamiento de la misma, en función de la época, la zona o del tipo de producto (Iranzo 2005: 69). Los romanos eran conscientes de esta variedad, ya que denominaban sal nativus o naturalis a la obtenida de forma natural y sal facticius a la conseguida por el calentamiento artificial de la salmuera. De igual forma, explotaban tanto la sal flumen, la salmuera de pozos salados o ramblas, como la sal fossilis o sal presente en la tierra (Morère 1994).

La sal obtenida de la salmuera va ligada a sus lugares de producción, las salinas. Encontramos principalmente dos tipos de estas: salinas marinas, generalmente las más explotadas en la Antigüedad y conocidas por su vinculación a la salazón de pescado y al transporte marítimo; y las salinas continentales, localizadas en tierras de interior y vinculadas a la presencia de manantiales, pozos o ramblas saladas. El interés de estas últimas radicaba en que no siempre era fácil de transportar la sal a zonas de interior, de ahí que fuese necesario explotar recursos salinos continentales. Sin embargo, estos espacios han sido progresivamente abandonados en detrimento de las salinas litorales debido a sus mayores dificultades de mecanización e industrialización (Iranzo 2006: 222). La sal procedente de explotaciones continentales ha ido destinada mayoritariamente al ganado de gran tamaño (ovicaprino, equino, suíno y bovino), coincidente con la cabaña ganadera existente en el mundo ibérico (Iborra 2004). Recordemos que los carnívoros no requieren de ingesta de sales puesto que están bien presentes en su propia dieta, algo que no sucede igual con los herbívoros o los propios humanos. Se ha calculado que un humano adulto puede consumir entre 3 y $7.5 \mathrm{~kg}$ de sal anuales (Multhauf 1985).

Presente en los cinco continentes, la sal es un elemento consumido por los seres humanos desde la Prehistoria, sobre todo a partir del Neolítico con la domesticación de los animales, el desarrollo agrícola y el consiguiente proceso de sedentarización. El descenso de aportes de carne en favor de cereales y legumbres requería de la ingesta añadida de sales minerales (Carrilero 2005). Hay interesantes ejemplos de explotación de la sal en el Neolítico tanto en ámbito europeo como peninsular, donde destacan los hallazgos en torno a la Muntanya de Sal de Cardona (Fíguls y Weller 2017). En el antiguo Egipto se utilizaba un tipo de sal natural, el natrón procedente del Wadi Natrum, para la momificación de cadáveres (Sandison 1963, Ikram 2010) y la producción cerámica (Nicholson 2009). Si bien no aparece reflejada en las Tablillas de Yale, algunos autores no dudan de que fuese un ingrediente presente en la cocina mesopotámica (García Lenberg 2005: 116). Del mismo modo, se tiene atestiguada su producción en China desde hace 6.000 años (Nenquin 1961). En la Edad del Bronce y la Edad del Hierro centroeuropeas sobresalió la cultura del Hallstatt, principalmente por la explotación minera 
de estos recursos (Kern et al. 2013). No obstante, es a partir de la Edad del Hierro y, sobre todo, de los procesos de colonización mediterránea cuando se produce una marcada aceleración. La búsqueda de sal era uno de los motivos que justificaba tan arduas empresas hacia los confines del mundo conocido (Plácido 2005). En este sentido, un importante número de fundaciones coloniales fenicio-púnicas se encontraba próximo a salinas marinas, lo que permitía instalar factorías de salazón de pescado: Carthago, Gadir, Motya o Ebussus, entre otras.

$\mathrm{Al}$ igual que en otros múltiples aspectos, el volumen de información sobre su uso y explotación se incrementa considerablemente en el mundo romano, que recoge la herencia fenicio-púnica de la utilización de sal marina en sus cetariae de salazón y garum (Molina 2005). La explotación continental siempre aporta menor información, en parte porque seguramente estaría menos desarrollada (Plin. Nat. 31.89), aunque también tenemos datos de manantiales de agua salada donde la sal se obtenía gracias a la evaporación solar (Strab. 4.1.7). Es por todos conocido el papel de la sal en el desarrollo de la ciudad de Roma, con la explotación de las salinas de Ostia desde momentos tempranos, así como la importancia de la Vía Salaria en el transporte de la sal entre el Adriático y Roma. Un punto importante en la ciudad romana sería el antiguo Foro Boario, explanada estratégica entre colinas y con agua disponible por la presencia del Tíber, donde se encontrarían los almacenes para la sal y se concentraría el ganado consumidor de este recurso (Battaglini 2005: 68-71). El término "salario" proviene del latino salarium en referencia al pago que recibían los legionarios. Del mismo modo, la sal era un símbolo de fecundidad, dándose a los enamorados el nombre de $s a$ lax (Arias 2005). Son numerosas las evidencias de explotación de la sal en época romana (García Vargas y Martínez Maganto 2017), como por ejemplo en ámbito hispano las espectaculares salinas recuperadas en Vigo (Castro Carrera 2006) o las estructuras tardorrepublicanas documentadas en Cardona (Pancorbo 2019).

Por lo que respecta a la península ibérica en la época que nos ocupa en este estudio, se ha documentado producción de sal continental en diversas áreas celtas, celtiberas e iberas, pero en la mayoría de los casos se trata de leves pinceladas, con escasas excavaciones arqueológicas y datos muy difusos (Cerdeño y Pérez de Inestrosa 1992, Valiente et al. 2017). Sin duda, los estudios desarrollados en los últimos años por J. Terán en el Sistema Ibérico Central suponen un gran avance en cuanto a metodología e información, con una interesante perspectiva diacrónica desde la Prehistoria hasta época contemporánea (Terán 2011, 2014 y 2017a).

\section{ZONAS DE ESTUDIO: MESETA DE REQUENA-UTIEL (VALENCIA) Y LA MANCHUELA (CUENCA)}

La meseta de Requena-Utiel, en el interior de la provincia de Valencia, constituía el territorio de la antigua ciudad ibérica de Kelin / Los Villares (Caudete de las Fuentes). Las excavaciones en este yacimiento desde mediados del siglo pasado han sacado a la luz restos de un oppidum de unas 10 ha, con toda una serie de elementos que permiten abogar por su estatus de lugar central, como pueden ser la concentración de bienes de prestigio, un urbanismo desarrollado, la acuñación de moneda o numerosas muestras de escritura (Mata 1991 y 2019). Y, de forma paralela a las excavaciones, las campañas de prospección desarrolladas en la comarca desde los años 90 han permitido conocer un denso y jerarquizado poblamiento ibérico, con más de 200 yacimientos de entre los siglos VII y I a.C. Son múltiples los ámbitos de estudio de este territorio desde una perspectiva económica: agricultura, ganadería, metalurgia, alfarería, apicultura, aprovechamiento de recursos forestales y, también, explotación de la sal (Moreno 2011: 182-185, Quixal 2015: 141).

Esta comarca presenta una geografía heterogénea, con abundancia de llanos y planicies en el centro y depresiones de ríos y sierras en los extremos, dándole una clara configuración de meseta, que no deja de ser un apéndice de la meseta castellana (fig. 1). A lo largo de la misma encontramos abundantes afloramientos geológicos del Keuper, compuestos por materiales blandos (margas, arcillas y yesos) que están muy expuestos a la erosión y generan profundos barrancos, muy estériles

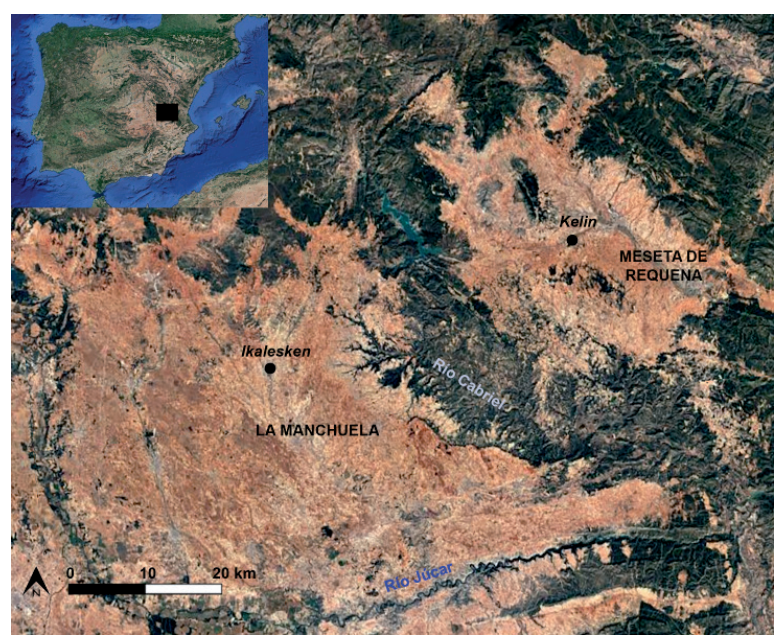

Figura 1. Ortofoto de las zonas de estudio (Google Earth). 


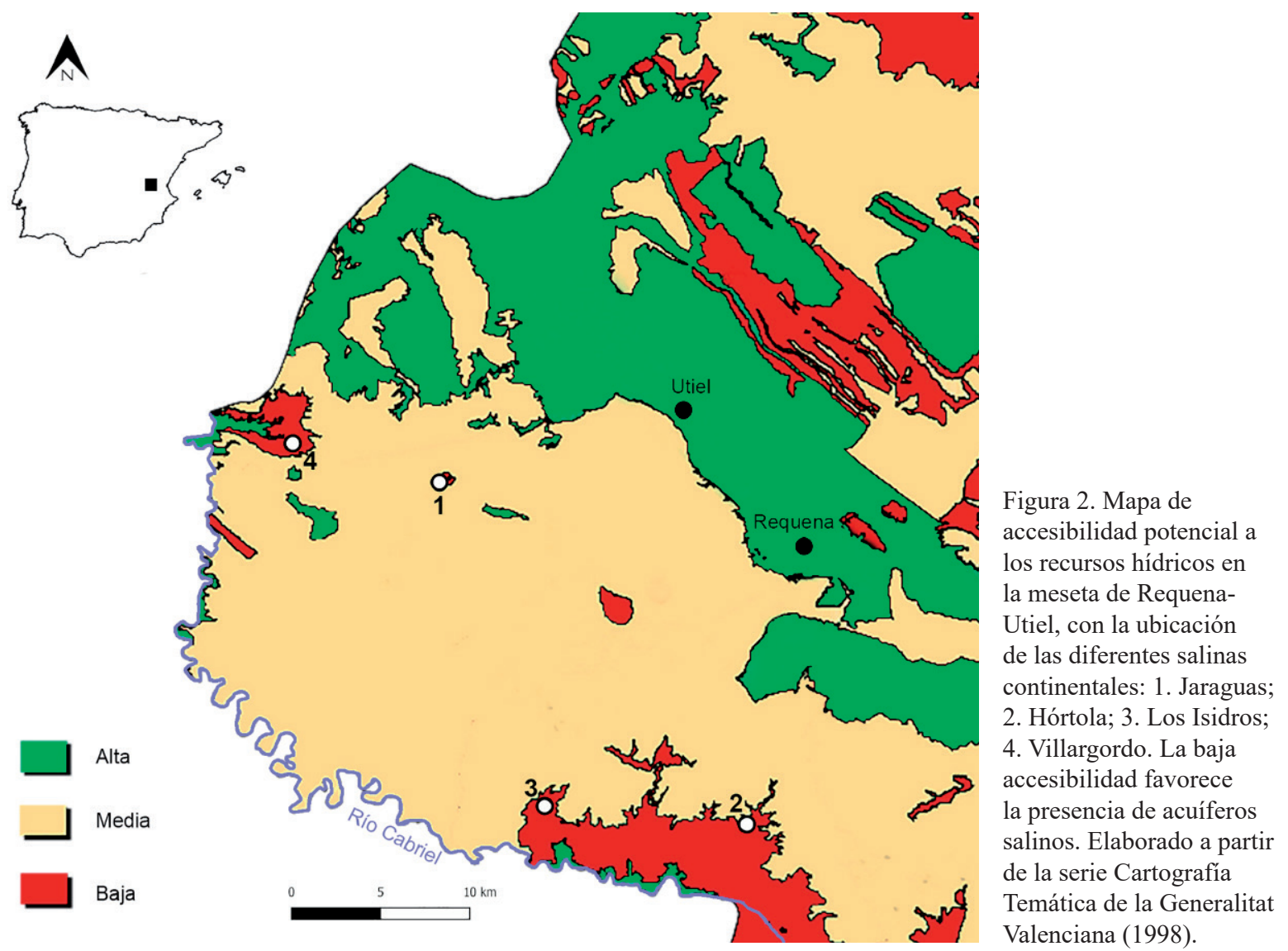

(bad lands) (Piqueras 1997: 126). Estos materiales son muy poco permeables y su contacto con las aguas de infiltración y percolación del subsuelo provoca que se vuelvan salobres, emergiendo a la superficie en forma de ramblas o manantiales salinos. La toponimia tradicional da buena muestra de la abundancia de este tipo de procesos geológicos por toda la comarca, dado el extenso número de nombres como Fuente Salada, Rambla de las Salinas, El Saladar, Barranco Salado, Rambla Salada, Charco Salado, Cañada del Salitrar o La Salobreja (Argilés 2006), por citar sólo unos cuantos. Son muy frecuentes los cursos irregulares de agua, popularmente llamados "tollos", que en ocasiones presentan charcas salobres (Yeves 2000). No obstante, debemos ser conscientes de que solo un pequeño porcentaje de todos estos saladares, espacios naturales salinos, fueron transformados en salinas, espacios antrópicos que forman parte del paisaje cultural.

En la meseta de Requena-Utiel existen hasta un total de cuatro explotaciones salineras históricas, siendo la comarca de la provincia de Valencia con un mayor número (fig. 2). Concretamente son las salinas continentales de Jaraguas (Venta del Moro), Hórtola y Los Isidros (Requena) y Pajazo (Villargordo del Cabriel), todas ellas activas hasta el siglo XX (Iranzo 2005). A las cuatro se pueden sumar otras de carácter irregular e incluso clandestino, como sucedía en la aldea requenense de Casas del Río (Iranzo 2006: 242). La comarca presenta un clima idóneo para este tipo de explotaciones, con veranos cálidos y secos e inviernos cortos y no excesivamente duros. Del mismo modo, existe un régimen de vientos favorables, así como lluvias escasas durante los meses de producción, exceptuando puntuales tormentas estivales. Las grandes extensiones de masa forestal permitirían tener también el combustible requerido para calentar la salmuera.

Por otro lado, en la ribera contraria del río Cabriel encontramos la región de La Manchuela. Es una zona de transición entre la meseta de Requena-Utiel, la meseta castellana y la serranía conquense. Está bien delimitada por los cursos de los ríos Júcar (Sur y Oeste) y Cabriel (Este), teniendo las tierras intermedias carácter de llanura (fig. 1). A nivel administrativo está subdividida a su vez en dos comarcas que comparten el mismo 
nombre, una en la provincia de Cuenca y otra en Albacete. La propia meseta de Requena-Utiel formó parte de este territorio hasta su anexión a Valencia en 1851, si bien el profundo surco del río Cabriel siempre ha constituido una separación clara.

Por lo que respecta a este trabajo, nos centraremos en la mitad septentrional, la conquense, que constituía el territorio ibérico de Ikalesken. Toda la problemática historiográfica y arqueológica acerca de su localización y evolución se desarrollará en posteriores apartados. Se trata de un área escasamente estudiada a nivel de territorio, a diferencia de su vecina albacetense, donde sí se han realizado campañas de prospección y estudios de poblamiento (Sanz Gamo 1997, Soria et al. 2016). En La Manchuela conquense encontramos la importante mina de sal de Minglanilla (La Pesquera).

\section{SALINAS CONTINENTALES Y MINAS DE SAL: DATOS ARQUEOLÓGICOS, HISTÓRICOS Y ETNOGRÁFICOS}

Los espacios de explotación de la sal que han llegado a nuestros días están compuestos por toda una serie de elementos etnográficos, conservados de mejor o peor forma (fig. 3). En el caso de las salinas continentales, su funcionamiento se basa en la existencia de un manantial o pozo salado, que da inicio a un sistema de decantación y canalización de la salmuera hacia una serie de estructuras de deposición como calentadores, albercas para buscar una mayor saturación de la sal en líquido y cristalizadores, balsas poco profundas donde el calor solar permitía la evaporación del agua y su separación de la sal (Iranzo 2005). El producto, una vez obtenido, muchas veces necesitaba una molturación inicial mediante molinos o morteros. En el caso de las minas se pueden conservar restos de galerías y pozos, aunque frecuentemente el paso del tiempo ha sellado sus entradas. De forma anexa podían existir otras estructuras, como almacenes, refugios o las propias viviendas de los trabajadores.

En este tipo de paisajes antropizados con una larga diacronía siempre es difícil determinar en qué momento comenzó la explotación, de forma parecida a lo que sucede en canteras o minas (Lorrio et al. 1999: 163-164, Martínez Maganto 2012: 17, Quixal 2020: 163). Solo en contados casos presentan materiales asociados, de ahí el carácter excepcional de algunos de los conjuntos que aquí presentamos, por tener materiales ibéricos o romanos directamente relacionados con los lugares de extracción. Materiales vinculables con la explotación salinera ibérica podrían ser tinajas, tinajillas y lebetes para lavar y depurar la sal, así como ollas para cocer la salmuera y facilitar los procesos de ignición o briquetage (Weller 2015: 188-189), uno de los métodos más antiguos de conseguir la evaporación de la sal de forma artificial (Iranzo 2005: 70). No obstante, existirían otros mecanismos para conseguir la ignición sin utilizar recipientes cerámicos (Weller 2004: 99-101). Del mismo modo, los molinos pétreos o morteros cerámicos podían utilizarse para machacar la primera sal gruesa y conseguir un producto más fino (Weller 2015: 191).

Los espacios salineros históricos que integran el presente trabajo son los siguientes:

\section{Salinas de Jaraguas o de Lolita (Venta del Moro, Valencia)}

Son las salinas más importantes de este estudio por su vinculación directa con materiales ibéricos. Se encuentran en el centro de un potente diapiro triásico redondo, de unos $700 \mathrm{~m}$ de diámetro (Piqueras 1997: 157-158), y se abastecen del manantial de La Salobreja dentro del valle de La Albosa. Se encuentran a tan solo $1 \mathrm{~km}$ de la aldea venturreña de Jaraguas y fueron explotadas por los vecinos de esta localidad hasta mediados del siglo pasado.

Las estructuras etnográficas se conservan relativamente mal (fig. 3.1). El eje de la producción era un manantial de agua salada, con pozo central en forma de embudo y de unos 5-6 $\mathrm{m}$ de profundidad. El agua se extraía y vertía a las diferentes balsas familiares para que cristalizara, siendo posteriormente recogida en cestos o capazos y transportada al molino. Para poder recoger la sal durante los meses de invierno en los que el calor y las horas de luz disminuían considerablemente, se utilizaban unas planchas elevadas que eran calentadas con fuego (Panadero 2001).

Diversos autores en el pasado ya han hicieron alusión al hallazgo de monedas y cerámicas en las proximidades de estas salinas cercanas al lugar central, Kelin (Latorre 2001, Iranzo 2005: 164, Hortelano 2007: 276). En el Museo de Prehistoria de Valencia hay depositada un hacha de piedra pulida neolítica o eneolítica procedente de esta localidad (fig. 4.8), algo bastante indicativo, dada la escasez general de ese tipo de materiales en el interior valenciano. Se ha demostrado que este tipo de piezas fue utilizado en la minería de la sal, de ahí su abundancia alrededor de los lugares de extracción (Fíguls y Weller 2017). Fueron prospectadas en los años 1994 y 2000, siendo datadas como Ibérico Pleno (Moreno 2011: 182-183), si bien es algo aproximado y difícil 

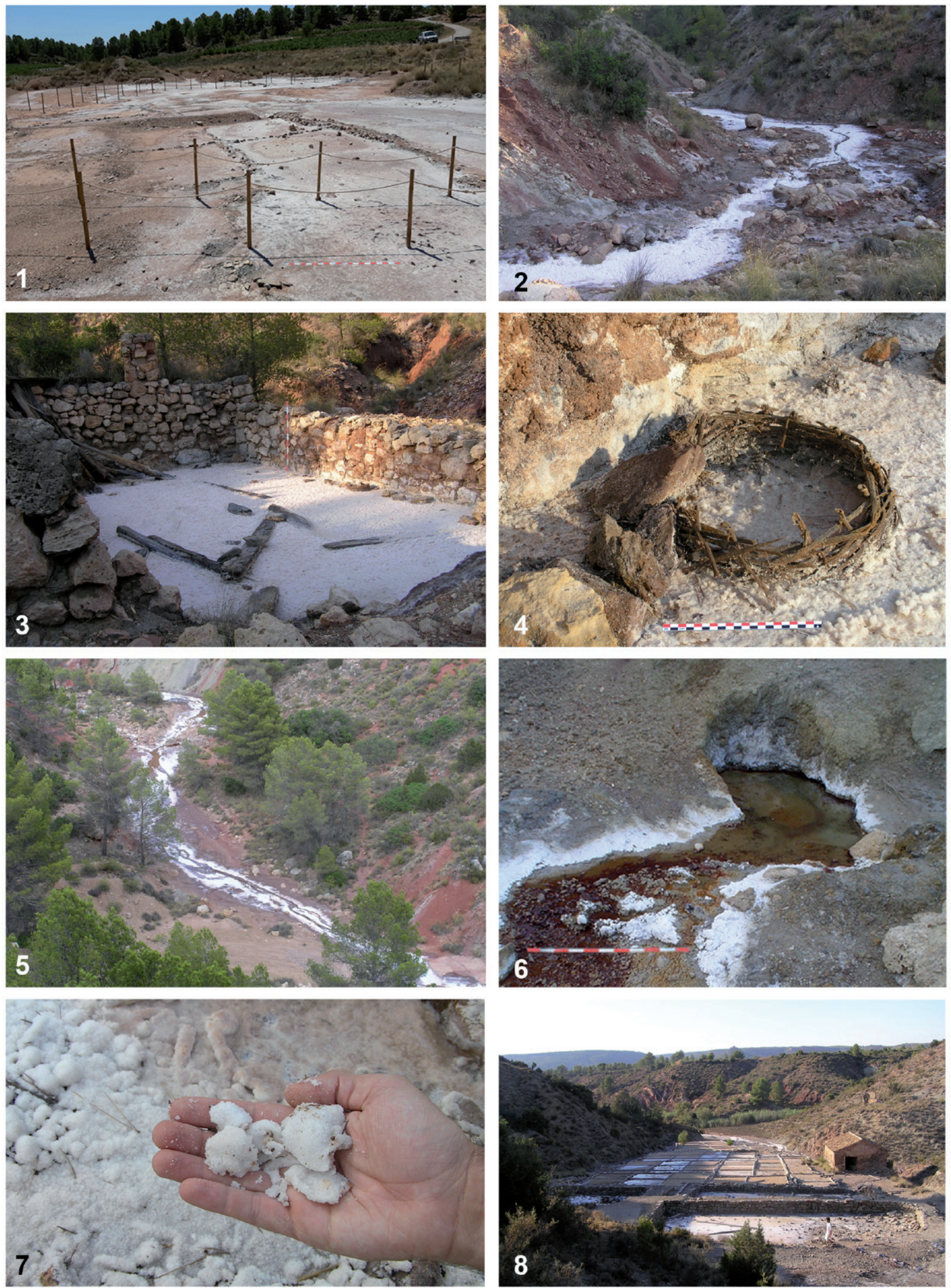

Figura 3. Fotografías de las diferentes salinas continentales de la meseta de Requena-Utiel: Jaraguas (1), Hórtola (2 a 4), Los Isidros (5 a 7) y Villargordo del Cabriel (8). 


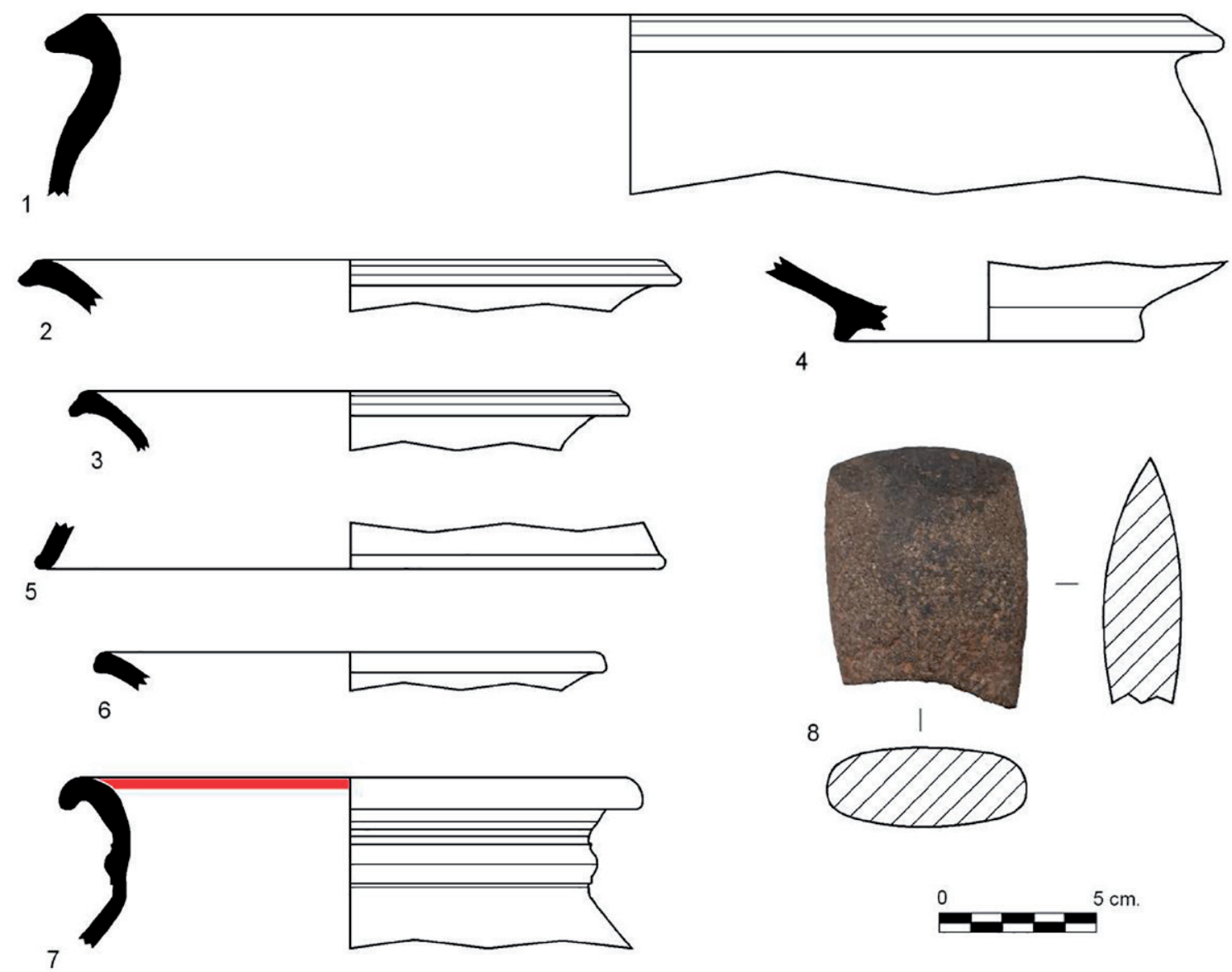

Figura 4. Lámina de materiales arqueológicos procedentes de los entornos de las salinas de Jaraguas (1 a 6 y 8) y Hórtola (7).

de determinar ante la carencia de fósiles directores claros. El material ibérico aparece disperso a lo largo de los campos de cultivo de su alrededor y, de forma significativa, es especialmente abundante en los terrenos de las propias salinas. La mayoría son fragmentos cerámicos informes, identificándose únicamente como tipos un lebes (fig. 4.1), dos tinajillas (fig. 4.2 y fig. 4.3), una tapadera (fig. 4.5) y una olla (fig. 4.6).

\section{Salinas de Hórtola (Requena, Valencia)}

Las salinas de Hórtola se ubican en plena depresión hacia el río Cabriel, encajadas en el barranco de las Salinas (fig. 3.2). Presentan dos manantiales naturales que abastecen diferentes calentadores (fig. 3.3 y 3.4). Se producía una sal bastante gorda, de mala calidad y dedicada a procesos de salado y alimentación del ganado; sin embargo, fueron las que tuvieron una producción mayor de las cuatro aquí tratadas. Se tiene documentado el comienzo de su explotación en el siglo XIII y fue abandonada en los años 60 (Hortelano 2007: 281) (fig. 5). Además, cerca de las salinas existe un importante manantial de agua dulce. Se recuperó material arqueológico romano en sus inmediaciones al realizarse obras de construcción de un camino (Quixal 2015: 65-66). Destaca el hallazgo de sigillata hispánica y sudgálica, cerámica de cocina, un fragmento de hebilla de bronce y una piedra de molino circular. En nuestra visita en 2010, momento en el que la zona se hallaba en pleno proceso de reforestación, tan solo pudimos localizar un fragmento de olla de cocina romana y una tinajilla ibérica con baquetón, típica de época tardía (fig. 4.7).

\section{Salinas de Los Isidros (Requena, Valencia)}

Las salinas de Los Isidros están encajadas en la Rambla Salada requenense, en medio de la cual surge el manantial (fig. 3.5 a 3.7). La salmuera circula de forma natural 


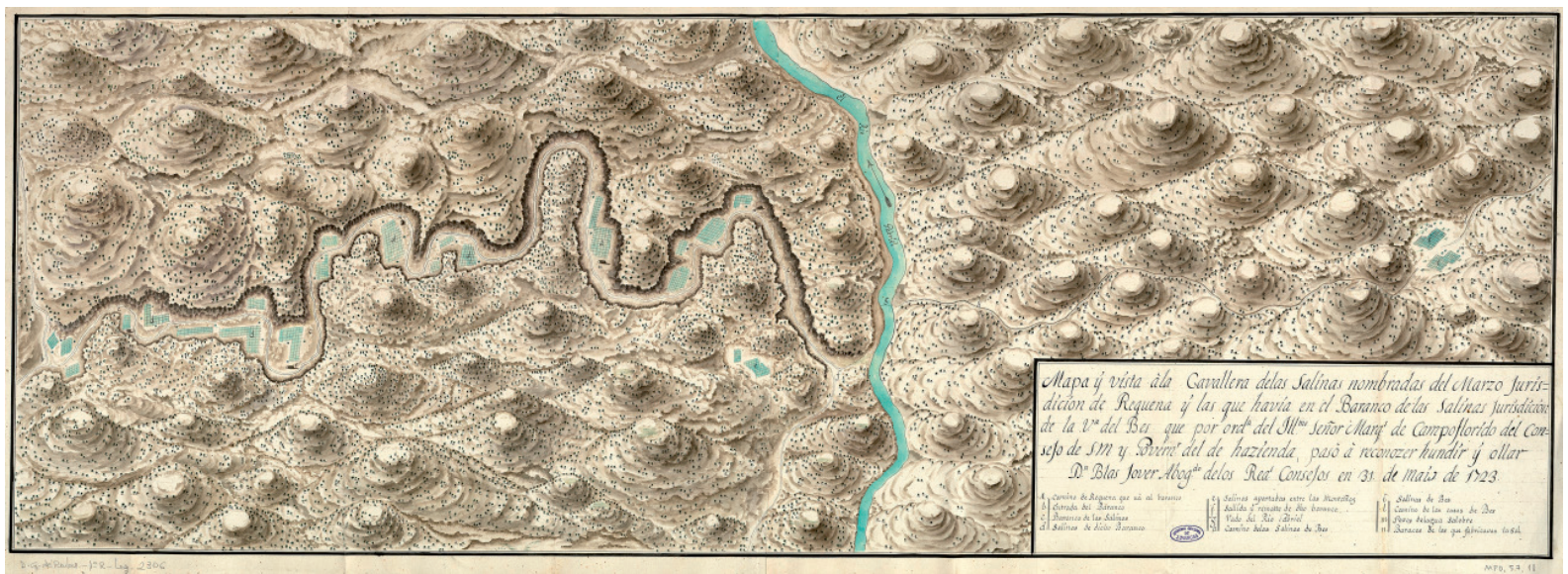

Figura 5. Mapa histórico de las salinas de Hórtola y Casas de Ves en 1723 (Archivo General de Simancas).

por el lecho de la rambla, por lo que se puede, y seguramente se podría en el pasado, recoger la sal durante los meses de calor sin requerir de ninguna transformación (Iranzo 2005: 179-186). Fueron abandonadas en los años 70 del siglo pasado. En la prospección de su entorno no se localizó ningún yacimiento arqueológico.

\section{Salinas del Pajazo o de Villargordo (Villargordo del Cabriel, Valencia)}

Estas salinas se encuentran en plena Rambla Salada villargordeña. Fueron explotadas desde el Medievo y estuvieron en activo hasta los años 90 del siglo pasado. A nivel etnológico, son las más interesantes y un elemento patrimonial digno de ser puesto en valor (fig. 3.8). Tienen unas dimensiones considerables y una compleja estructura compuesta por diferentes calentadores, numerosos cristalizadores y un almacén. Sin embargo, ni en sus propios terrenos ni en los campos de sus proximidades se ha recuperado material arqueológico antiguo.

\section{Mina de sal de Minglanilla (La Pesquera, Cuenca)}

Tal y como hemos apuntado, al otro lado del río Cabriel existía una importante explotación de sal, en este caso en forma de mina (Palomero 1987). Estuvo en activo, al menos con seguridad, desde el siglo XVI y fue abandonada progresivamente en la primera mitad del XX (fig. 6). Algunos autores defienden que la sal obtenida era la que la que históricamente se destinaba para consumo, tanto en la zona conquense como en la requenense, mientras que las salinas continentales abastecerían principalmente al ganado (Hortelano 2007: 280). La entrada al pozo principal se realizaba por una escalera de caracol, hoy perdida, y también contaban con unas salinas en superficie (Argilés 2006, 390). No se ha documentado material arqueológico ni en la mina ni en sus inmediaciones, aunque hay un alto nivel de erosión y modificaciones en el terreno (Terán 2017a: 148).

Las minas de sal gema no son espacios relativamente frecuentes. Existieron otras en Santa Cruz de Moya (Cuenca), donde se tiene documentada la producción desde el siglo XIX hasta mediados del XX (Terán 2017a: 149-150), aunque también aparece una posible primera explotación en el siglo XVI según las Relaciones Topográficas de Felipe II (Carrasco y Hueso 2006: 92). Del mismo modo, en Fuentealbilla, en La Manchuela albacetense, existen unas importantes salinas que posiblemente fueron también explotadas desde antiguo, tal y como demuestra el denso poblamiento ibérico a su alrededor (Soria et al. 2016). Por último, en la cercana localidad de Casas de Ves (Albacete) también existían unas salinas, aprovechadas al menos desde el siglo XVIII (fig. 5). A pesar su interés, todos estos casos no serán tratados por sobrepasar los límites geográficos del presente estudio.

\section{APROXIMACIÓN A LAS DINÁMICAS POBLACIONALES Y TERRITORIALES EN TORNO A LA SAL EN LA EDAD DEL HIERRO}

De forma paralela a lo desarrollado en múltiples trabajos previos sobre la vida económica de los iberos en estas tierras, nos interesa la actividad salinera tanto por 


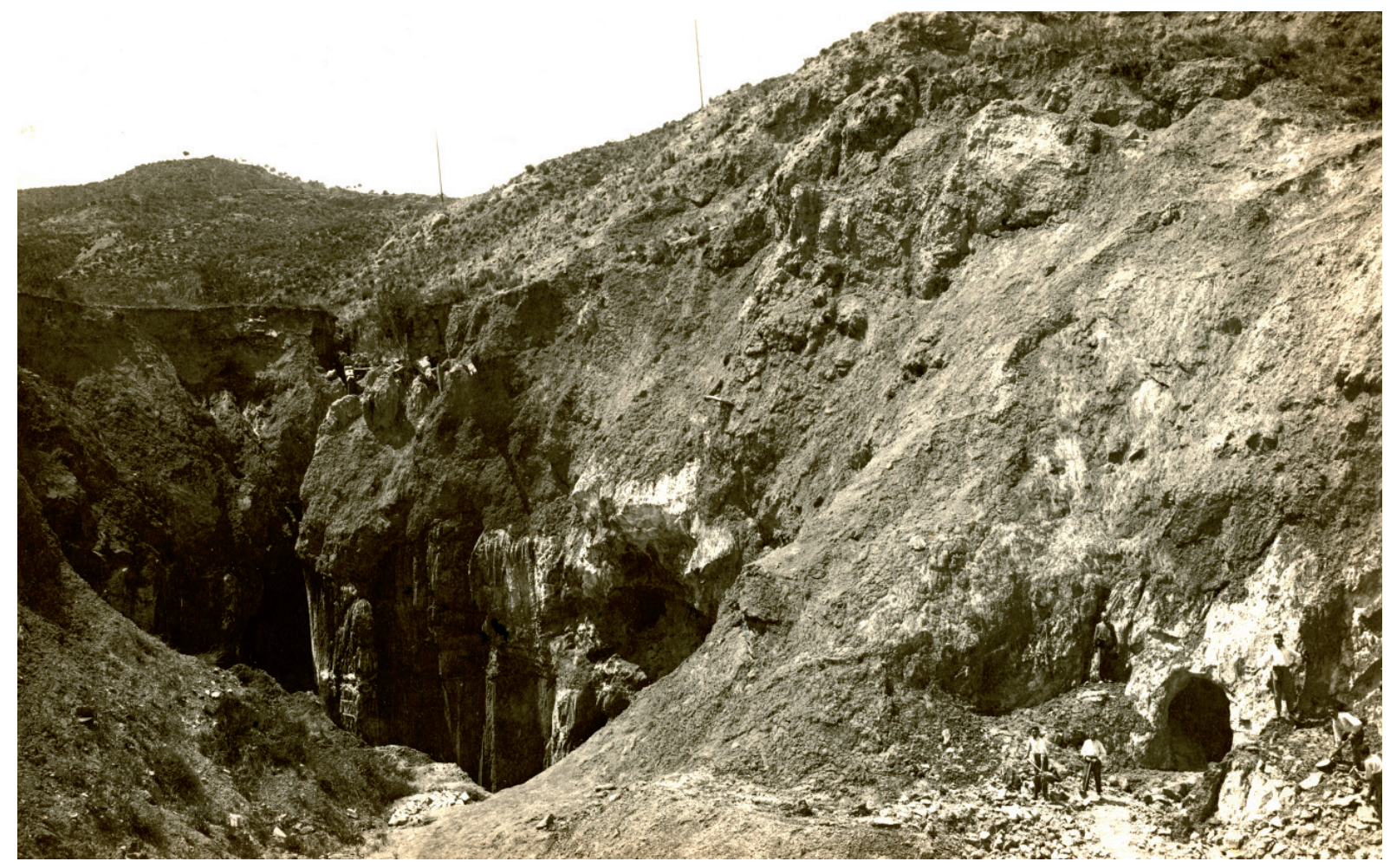

Figura 6. Fotografía de la mina de sal de Minglanilla en 1928 (Archivo de la Imagen de Castilla-La Mancha, Fondo Fotográfico Escobar).

lo que supone en sí misma como por su vinculación a nivel territorial. Las minas, salinas y saladares representaron algo más que meros puntos de obtención del preciado "oro blanco", puesto que también fueron importantes catalizadores de poblamiento y, sobre todo, de una compleja red de caminos y veredas ganaderas. Centrándonos en el territorio de Kelin por tener mejores datos tanto cuantitativa como cualitativamente, compararemos las localizaciones de las salinas con las dinámicas poblacionales y de movilidad planteadas en trabajos anteriores con ayuda de Sistemas de Información Geográfica (GVSIG y GRASS) (Quixal 2015). Esto nos permitirá conocer por dónde podrían transcurrir las principales vías de comunicación regionales, dentro del territorio de Kelin, y suprarregionales, de Kelin con otras ciudades ibéricas vecinas (fig. 7).

En su tesis doctoral, A. Moreno ya hizo un análisis de los entornos de los principales espacios salinos, viendo como dentro de un radio de $5 \mathrm{~km}$ alrededor de estas salinas encontrábamos yacimientos ibéricos de diferente entidad (Moreno 2011: 182-185). En este sentido, las salinas de Jaraguas estaban cerca de asentamientos rurales ibéricos como La Atalayuela, Los
Chanes y, sobre todo, la Casa Sevilluela, posible aldea en el llano donde se documentaron abundantes cerámicas y escorias de hierro (Quixal 2015: 67). Las salinas están enclavadas en el cruce entre dos importantes veredas ganaderas históricas con dirección Este - Oeste (Vereda de la Mancha a Valencia) y Norte - Sur (Vereda de Cuenca a la Muela de Cortes), además de encontrarse próximas a la dehesa de Sevilluela (Hortelano 2007: 279). A su vez, estarían muy cerca de la principal vía de vertebración del territorio paralela al curso del río Magro y a $7 \mathrm{~km}$ de la propia ciudad de Kelin, lo que equivaldría a un desplazamiento de aproximadamente 90 minutos. Siguiendo lo que planteamos hace unos años, quedarían fuera del entorno inmediato o área de producción directa de Kelin, pero sí dentro de su área de captación (Moreno y Quixal 2009).

En el caso de las salinas de Hórtola, encontramos muy cerca el asentamiento rural de las Casas del Carrascalejo (Moreno 2011: 182-185, Quixal 2015: 65). Este núcleo estaba próximo a la principal vía de comunicación del territorio de Kelin con su vecino meridional, el oppidum de Castellar de Meca (Ayora, Valencia). Justamente las salinas podrían considerarse como un 


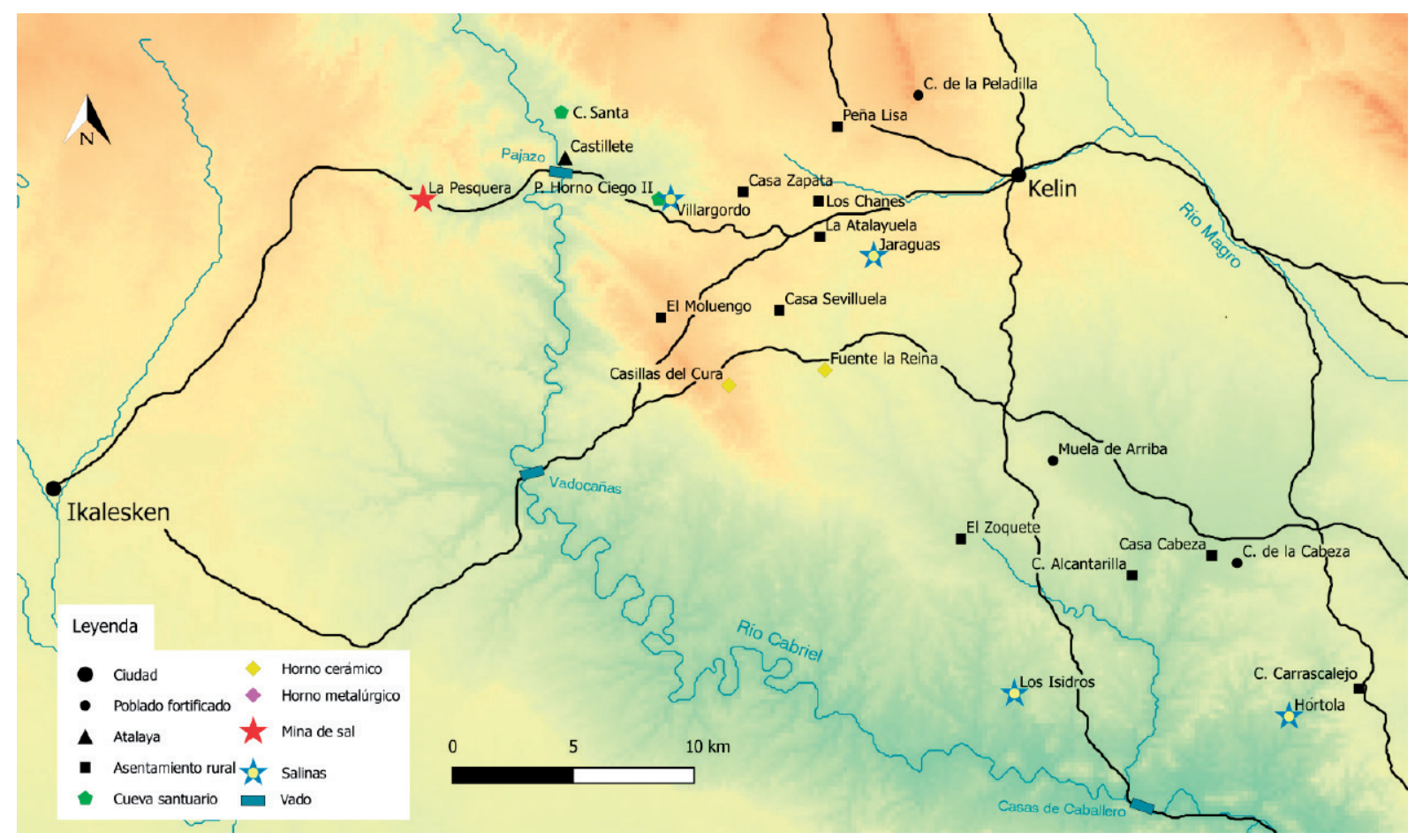

Figura 7. Mapa con las diferentes salinas en relación con los yacimientos ibéricos citados en el texto, así como con los principales caminos y vados pretéritos. Elaborado con QGIS.

espacio liminal, de los últimos pertenecientes a este territorio poco antes de comenzar la depresión hacia el valle de Cofrentes, espacio donde también existen otras salinas, las de San Javier (Cofrentes, Valencia). Por lo que respecta a las salinas de Los Isidros, están cerca de otra importante vía hacia el Sur y no muy lejos del vado de Casas de Caballero. Al cruzar el Cabriel por ese punto se llegaría a La Manchuela albacetense, zona donde están las anteriormente citadas salinas de Casas de Ves y Fuentealbilla.

En el caso de las salinas de Villargordo, de nuevo encontramos esa vinculación con una importante zona de paso. En su entorno tenemos pocos datos de poblamiento y únicamente son asociables con el asentamiento iberorromano de Casa Zapata (Villargordo del Cabriel). Este yacimiento es una gran extensión de material disperso, de cronología tanto ibérica como romana, en la misma rambla que las salinas, solo que 3 $\mathrm{km}$ al Este. De allí procede una conocida inscripción funeraria latina (Corell 1996: 212-214), siendo uno de los mejores ejemplos de continuidad temporal en el hábitat entre época ibérica y romana. No obstante, el yacimiento más cercano a estas salinas no es un lugar de hábitat, sino una cueva-santuario, concretamente la del Puntal del Horno Ciego; una de las cuevas rituales mejor conocidas del mundo ibérico valenciano, donde se recuperaron en 1974 gran cantidad vasos caliciformes y otros objetos que no dejan duda del uso sacro del lugar (Gil-Mascarell 1977). Un poco más lejana se encuentra la Cueva Santa (Mira, Cuenca), otra cueva ritual ibérica (Lorrio et al. 2006). Este tipo de espacios los encontramos en zonas periféricas de los diferentes territorios; en ambos casos muy próximas al río Cabriel, límite natural del territorio de Kelin (Machause y Quixal 2018). Por último, también destaca su proximidad al antiguo vado / puente del Pajazo, uno de los pasos principales para cruzar el Cabriel y dirigirse hacia el Oeste (Quixal y Moreno 2011: 18-19), comunicando con otro de los espacios salinos aquí analizados, la mina de sal de Minglanilla. Tanto las salinas de Villargordo como la mina de sal de Minglanilla se encuentran a poca distancia de dicho paso (unos 5 y $6 \mathrm{~km}$ respectivamente).

Las minas de sal de Minglanilla han llamado la atención de estudiosos desde tiempo inmemorial, siendo relacionadas en infinidad de ocasiones con el topónimo antiguo de Egelasta (Palomero 1987). Este es recogido en las descripciones de Plinio (Nat 31.39.80), Ptolomeo (2.6.56) y Estrabón (3.4.9), aunque con fuertes contradicciones entre unas y otras, de ahí que sobre su 
ubicación se haya generado un denso debate con opiniones muy diferentes. Ya a mediados del siglo XIX se planteaba que:

Iniesta es la Salaria de Ptolomeo ó Egelasta de los romanos. Plinio la nombra diciendo que entre los muchos géneros de sal que se conocen, los médicos le daban la palma à la de Egelasta. La jurisdicción de Iniesta llegaba antiguamente hasta Minglanilla, cuya mina de sal de piedra en la inmensa longitud y laberinto de sus galerías y diafanidad de sus glebas indican ser la mencionada por Plinio. Es verosímil que los fenicios comenzaran à esplotar la mina de sal de piedra de Iniesta, y que esplotando los romanos la mina para el Estado, le cambiaron el nombre en Salaria, cual la llamó Ptolomeo (Pruneda 1869: 36).

No obstante, algunos autores la situaron en el Sureste, en relación con el Campus Spartarius, según las informaciones extraídas de itinerarios antiguos y descripciones geográficas de autores clásicos. Se planteó su ubicación en el Llano de la Consolación (Montealegre del Castillo, Albacete) por la cercanía de la laguna del Saladar (Corral-Rubio, Albacete) (Sillières 1977), así como en Yecla (Murcia) (Pérez-Rojas 1978). La disparidad de información aportada por Ptolomeo, que ubica Egelasta en el territorio de los Carpetanos, ha llevado incluso a plantear que pudiesen ser dos núcleos distintos.

Sin embargo, solo un reducido número de autores ha hecho hincapié (Terán 2017a y b), a nuestro parecer de forma muy acertada, en la necesidad de concentrar la atención en la forma en la que Plinio, posiblemente la fuente más fiable de las mencionadas, describe las características del proceso de extracción de la sal en Egelasta:

También en Hispania Citerior, en Egelasta, se extrae en bloques casi transparentes una sal a la que hace ya tiempo que muchos médicos consideran la mejor entre todos los tipos de sal (Plin. Nat. 31.39.80).

Es decir, no sería una explotación de la sal en polvo por evaporación, sino extracción en bloques de una mina de sal gema (Morère 1994: 237), espacios mucho menos abundantes como el que existió en Minglanilla.

Por otro lado, también se ha postulado que Egelasta sería la variante latina de época imperial derivada del ibérico Ikalesken (Luján 2003), conocida por sus importantes acuñaciones durante la época republicana (fig. 8). Aunque algunos autores defienden la lectura de la leyenda de estas acuñaciones como Ikalkusken (Villaronga 1962, 1980 y 1988), la
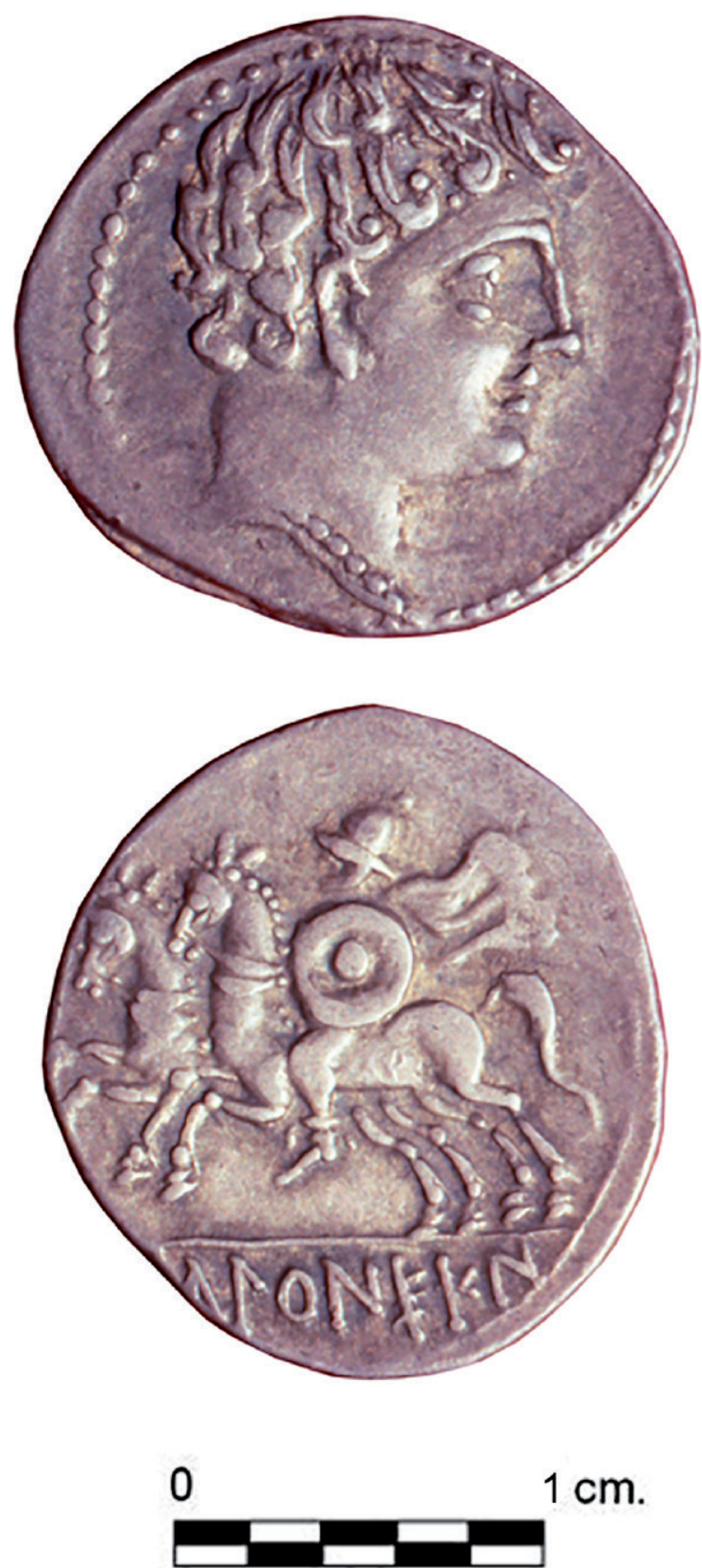

Figura 8. Denario de Ikalesken (Colección American Numismatic Society; fotografía de P. P. Ripollès).

mayoría sigue la propuesta planteada por Untermann (1975 y 1992) de Ikale(n)sken. Ikalesken sería el equivalente a un genitivo en las lenguas clásicas, mientras que la raíz del topónimo sería Ikales, de donde procedería la transformación fonética a Egeles (Quesada y García-Bellido 1995, De Hoz 2002, Terán 2017b: 5). 
Por lo tanto, las leyendas de estas monedas mencionarían posiblemente a una tribu, etnia o territorio y no tanto a un núcleo en sí (Ripollès 1999: 146), un dato que nos resulta bastante significativo y que retomaremos más adelante. Primero se conformaría el nombre étnico y posteriormente el topónimo, seguramente en relación con los cambios en los modelos de poblamiento generados a raíz de la llegada de los romanos (Luján 2003: 130).

La ceca acuñó denarios de plata y ases, semis y cuadrantes de bronce desde mediados/finales del siglo II a.C. hasta el contexto de las guerras sertorianas. Mientras los hallazgos de monedas de plata están distribuidos por la zona castellana, valenciana y andaluza, las acuñaciones de bronce, de carácter más local, están claramente concentradas en el área castellano-requenense (Martínez Valle 1995, Ripollès 1999, Gozalbes 2017). Todo ello indicaría que la ceca se encontraría necesariamente entre el curso de los ríos Cabriel y Júcar, un cruce de caminos entre las vías que conectaban la Alta Andalucía y el valle del Ebro (Arroyo et al. 1989: 385). Tal y como hemos indicado anteriormente, la teoría preponderante es ubicarla en la actual localidad de Iniesta (Villaronga 1988, Ripollès 1999, Gozalbes 2017), idea que compartimos. Son numerosos los hallazgos arqueológicos ibéricos y romanos en la localidad o en sus inmediaciones (Valero 1995 y 2010). El carácter de zona intermedia y cruce de caminos que tenían tanto la meseta castellana oriental como la meseta de Requena-Utiel explicaría, por ejemplo, la significativa abundancia de monedas de Castulo y determinadas concentraciones de monedas celtibéricas del valle del Ebro (Quixal 2015: 160).

Las acuñaciones ibéricas de Ikalesken están muy presentes en la meseta de Requena-Utiel, con 37 ejemplares entre Kelin y los yacimientos de su territorio, de forma especialmente interesante en aquellos, como la propia Kelin o Cerro Gallina (Requena, Valencia) (Arroyo et al. 1989), que jalonan la importante vía de comunicación entre el litoral y el interior siguiendo el valle del río Magro. Este camino pretérito uniría las ciudades ibéricas de La Carència (Torís, Valencia), $\mathrm{Ke}$ lin e Ikalesken (Albiach et al. 2007, Quixal 2012). En La Carència, posible ceca de Kili, se han documentado un total de 22 monedas de Ikalesken (Ripollès et al. 2013). También tenemos evidencias numismáticas en el Pico de los Ajos (Yátova, Valencia), posible poblado fronterizo del territorio de La Carència y punto de control del río Magro. Una vez atravesada la meseta de Requena-Utiel, la vía cruzaría el Cabriel por el vado de Vadocañas, justamente donde se localizaron varios depósitos de monedas de esta ceca (Martínez Valle 1995: 63). Otro conjunto monetario muy similar procede de otro vado tradicional de este mismo río, Villatoya. En el mundo antiguo, podían existir pequeños santuarios cerca de vados para que viajantes, comerciantes y pastores agradeciesen a las divinidades el poder cruzar (Alfaro 2001: 226-227). Quizás estos conjuntos tuviesen ese carácter votivo.

Por lo tanto, es interesante ver la vinculación entre algunos de los espacios salineros y las principales vías de comunicación, sobre todo la vía Este-Oeste, que seguía los cursos de los ríos Júcar y Magro desde el Portus Sucronem (Cullera, Valencia) hasta Ikalesken (Quixal 2012). Del mismo modo, hemos visto como las comunicaciones entre los territorios de Kelin e Ikalesken se articulaban gracias a la existencia de vados pretéritos sobre el río Cabriel, especialmente los de Pajazo y Vadocañas (Quixal y Moreno 2011). Por lo que aquí respecta, el Pajazo permitiría las comunicaciones con la mina de sal de Minglanilla, mientras que Vadocañas canalizaría la comunicación efectiva entre las dos ciudades. Parece claro que se trataba de territorios diferentes, aspecto definido desde los primeros estudios de territorio con polígonos Thiessen (Mata 2001), existiendo una frontera natural marcada en el curso del río Cabriel (Moreno 2011: 38-40, Quixal 2015: 169-173). Sin embargo, las áreas territoriales ibéricas estaban lejos de ser espacios cerrados, sino que presentaban entre ellas una fluida circulación de materiales y recursos (Mata et al. 2000). En el caso que aquí nos ocupa defendemos que el comercio y distribución de la sal sería un elemento destacado.

Por último, anteriormente ya comentamos la relación que tenía la sal en el pasado con determinados procesos industriales como la producción cerámica o metalúrgica. Nos parece sintomático como, por ejemplo, una de los hornos cerámicos más importantes detectados en el territorio de Kelin, La Maralaga (Sinarcas, Valencia), sea también conocido por el nombre de su partida, la Cañada del Salitrar (Lozano 2006). Sería interesante realizar analíticas a fragmentos cerámicos procedentes de dicho horno para determinar si las pastas cuentan con partículas salinas añadidas para obtener determinada propiedad o color. De igual forma, las salinas de Jaraguas se encuentran a $8 \mathrm{~km}$ de otro importante horno como es las Casillas del Cura, también en término de Venta del Moro (Martínez Valle y Castellano 2001). Recientemente, en el transcurso de las obras de construcción de un camino rural otro horno cerámico ibérico fue seccionado en el paraje de Fuente la Reina, $3 \mathrm{~km}$ más próximo a las salinas. En trabajos 
anteriores ya hemos puesto de manifiesto la importancia de las actividades metalúrgicas, principalmente siderúrgicas, desarrolladas en esta comarca durante la Edad del Hierro (Mata et al. 2009a, Quixal 2020). Del mismo modo, en el futuro será necesario realizar estudios arqueométricos que permitan determinar si la sal jugó algún papel en las mismas.

\section{CONCLUSIONES: SAL, TRASTERMINANCIA Y COMERCIO}

Estudiar actividades que dejan tan poco registro material como la producción de la sal conlleva la problemática de que se acaban generando más interrogantes que respuestas. No reviste dudas el hecho de que estos recursos comenzarían a ser explotados, cuanto menos, desde la Edad del Hierro en salinas continentales como las de Jaraguas u Hórtola, así como en la mina de sal de Minglanilla. Aunque se trata de escasos materiales, las cerámicas recuperadas en Jaraguas y Hórtola se podrían vincular a actividades de lavado de la sal e incluso ignición de la salmuera, según hemos descrito anteriormente. El volumen, los ritmos y los condicionantes sociales que esta actividad tuvo en la Antigüedad son por el momento difíciles de poder atisbar. Sin embargo, el análisis territorial de estos espacios y su vinculación con importantes veredas y vías de comunicación pretéritas nos permiten, al menos, plantear una serie de cuestiones referentes a la esfera económica ibérica.

La producción de la sal generaría importantes recursos a las familias implicadas en los territorios de Kelin e Ikalesken, por su conexión con las actividades ganaderas y comerciales. A nivel etnográfico, en las salinas requenenses generalmente eran las familias más pobres las que explotaban este recurso, ya que tenían pocas tierras y necesitaban completar su economía (Iranzo 2006: 237). No creemos que sea algo extrapolable al periodo aquí tratado, aunque muchas de las instalaciones tampoco poseerían un carácter superior al familiar o comunitario. Un nivel diferente tendría la mina de Minglanilla, con potencial capacidad de albergar una explotación amplia y de carácter industrial. La acuñación de gran cantidad de plata por parte de Ikalesken quizás también pueda leerse desde la perspectiva de la riqueza y prosperidad que la explotación de la sal, juntamente con su carácter de cruce de caminos, pudo proporcionar a esa comunidad o territorio después de la conquista romana; una riqueza de tal magnitud que llegaría a ser digna de mención por el propio Plinio y que llevaría a emitir moneda con el
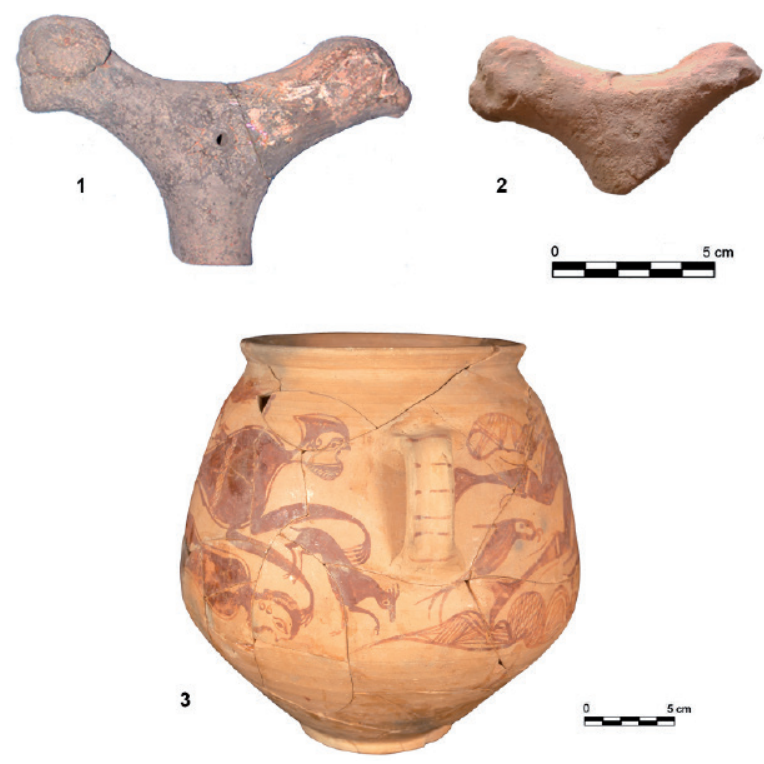

Figura 9. Representaciones de ovicápridos: 1. Mano de mortero de Kelin (Colección Museográfica Luis García Fuentes de Caudete de las Fuentes; fotografía de A. Moreno); 2. Mano de mortero de Los Chotiles (Sinarcas, Valencia); 3. Vaso de la Gigantomaquia de Kelin (Colección Museográfica Luis García Fuentes de Caudete de las Fuentes; fotografía de Gil-Carles).

nombre de la tribu o etnia en vez de con un topónimo concreto. Del mismo modo, las acuñaciones de bronce se podrían relacionar con las necesidades básicas derivadas de la explotación minera.

Muchas de las salinas están cerca de importantes veredas ganaderas. No es casualidad que dos de las veredas históricas más importantes se crucen justamente a la altura de las salinas de Jaraguas, con la importancia que tiene la sal para la alimentación del ganado. Hay interesantes paralelos históricos y etnográficos de cómo la presencia y explotación de los recursos salinos favorece el desarrollo ganadero de una zona (Bustos 1993) y la existencia de labores de pastoreo (Aranda 2016: 54). Sería una actividad que tendría ya importancia durante época ibérica según apuntan los registros faunísticos de los yacimientos excavados, dada la preponderancia de la cabaña ovicaprina y, en menor medida, bovina y equina (Iborra et al. 2010: 100-102). A nivel general, a pesar de este claro dominio, la presencia de ovicápridos en el arte es mínima (Mata et al. 2014: 12-15). Sin embargo, en el territorio de Kelin se han documentado dos manos de mortero ibéricas decoradas con un prótomo de carnero en uno de sus apéndices (Quixal 2018: 470-471) 
(fig. 9.1 y 9.2), así como la representación pictórica de una cabra en el conocido Vaso de la Gigantomaquia (Mata 1991: 131) (fig. 9.3). Que formen parte del corpus artístico y, por ende, del imaginario colectivo es un indicio de la importancia de la ganadería pastoril en la zona. Del mismo modo, la abundancia de fusayolas votivas en algunas cuevas-santuario del territorio llevó a plantear que las prácticas rituales allí desarrolladas podían estar vinculadas con el hilado y tejido de la lana (Martínez Valle y Castellano 1995: 526), uno de los principales productos obtenidos de esta cabaña ganadera.

Es complicado establecer la movilidad que tendrían los rebaños, ya que tanto la trashumancia, movimientos de más de $100 \mathrm{~km}$, como la trasterminancia son prácticas difíciles de rastrear arqueológicamente. En la Edad del Hierro la existencia de diferentes territorios y la conflictividad entre grupos pudo dificultar el libre tránsito de rebaños a gran escala. Sin embargo, algunos autores creen que sería precisamente en esta fase cuando los diferentes sistemas políticos en alza permitirían el establecimiento de pactos, de la misma manera que ocurría con los intercambios comerciales (Gómez-Pantoja y Sánchez Moreno 2003). De hecho, movilidad comercial y ganadera parece que pudieron ir de la mano en determinados territorios (Mederos y Ruiz Cabrero 2000-2001). Respecto a nuestra área de estudio, la zona de La Manchuela sí que parece más abierta a movimientos de largo recorrido, quedando insertada en la red trashumante documentada arqueológica y epigráficamente en época romana entre Sierra Morena y la sierra de Cuenca (Aranda 2016: 57). En la meseta de Requena-Utiel, por el contrario, pensamos que la trasterminancia sería la actividad principal, tal y como se ha defendido de forma general para el ámbito ibérico valenciano (Iborra 2004). En época moderna y contemporánea en este tipo de cotas medias (entre 400 y 1200 m s.n.m.) el pastoreo alternaba las zonas de cultivo en invierno con los montes y dehesas en verano, pero sin prácticamente salir de las regiones (Piqueras y Sanchis 1991: 205).

Del mismo modo, hemos podido corroborar que algunas salinas están relacionadas directamente con posibles caminos y vados pretéritos, elementos indispensables para la circulación de productos y el desarrollo de redes comerciales. El transporte y comercio de la sal jugaría un papel importante tanto a nivel regional como, muy probablemente, suprarregional. A lo largo de la historia la explotación de sal ha sido interesante tanto por los propios beneficios generados, como por la facilidad de gravar e instaurar impuestos sobre ella (Multhauf 1985: 2627). Sería, por lo tanto, un recurso fácil de controlar de una u otra forma desde un aparato estatal o protoestatal como el que podrían tener los territorios ibéricos participantes. Carecemos de datos suficientes como para poder plantear cuestiones relacionadas con la propiedad y los agentes participantes, un debate sí existente para época romana (García Vargas y Martínez Maganto 2006).

Otra cuestión importante sería el carácter permanente o estacional de los lugares asociados a estas salinas. Siguiendo lo planteado para determinadas zonas de la Celtiberia (Arenas y Martínez Naranjo 1999), lo lógico es pensar que se trataría de núcleos estacionales, quedando la producción concentrada en los meses de calor y abandonada durante el invierno. Ello explicaría la escasez de registro material, tanto mueble como inmueble. Hemos documentado dinámicas semejantes ligadas a otro tipo de producciones estacionales como la vitivinicultura, que generaron la aparición de establecimientos rurales auxiliares con carácter temporal para residir y trabajar durante la época de vendimia, quedando todo controlado en última instancia desde un asentamiento cercano de mayor entidad (Mata et al. 2009b). Algo parecido pudo darse en el caso de la sal. La producción fácilmente podría estar controlada desde algún asentamiento permanente, como la Casa Sevilluela para el caso de Jaraguas o, directamente, desde la propia ciudad de Kelin. Debemos esperar a que futuros descubrimientos y actuaciones arqueológicas puedan acrecentar nuestro grado de conocimiento de esta importante actividad económica del mundo antiguo.

\section{Agradecimientos}

Agradecemos la asesoría científica y aporte de datos para la elaboración del presente trabajo por parte de Ignacio Latorre (Archivo Municipal de Requena), Miguel Ángel Ponce (La Pesquera), Emilio Iranzo, Consuelo Mata y Pere Pau Ripollès (Universitat de València).

El presente estudio se ha desarrollado dentro del marco de un contrato de investigación postdoctoral VALi+D de la Generalitat Valenciana (2015-2017). La temática se inserta directamente en la línea de investigación sobre el poblamiento ibérico en la comarca de Requena-Utiel desarrollada por Consuelo Mata y su equipo, de forma paralela al proyecto de excavación en el oppidum de Kelin (Museu de Prehistòria de València $\mathrm{y}$ Universitat de València). 


\section{BIBLIOGRAFÍA}

Abarquero, F. J.; Delibes, G.; Guerra, E.; Palomino, A. J. y Del Val, J. (2010): Cuarenta siglos de explotación de sal en las lagunas de Villafáfila, Zamora (2500 a.C. - 1500 d.C.). Valladolid, Junta de Castilla y León.

Albiach, R.; Ledo, A.; Mata, C. y Requena, M. (2007): "Prehistòria i Història Antiga", en VVAA, Turís. Geografia, Història: 89-134. Valencia, Universitat de València.

Alexianu, M.; Curca, R. G. y Cotiuga, V. (2015): Salt Effect. Second Archeoinvest Symposium: From the ethnoararchaeology to the anthropology of salt. BAR International Series 2760, Oxford, Archaeopress.

Alfaro, C. (2001): "Vías pecuarias y romanización en la Península Ibérica”, en J. Gómez-Pantoja (coord.), Los rebaños de Gerión: pastores y trashumancia en Iberia antigua y medieval: 215-232. Madrid, Casa de Velázquez.

Aranda, J. A. (2016): “De pastores y caminos: trashumancia en el Alto Guadalquivir en época romana". Antiquitas 28: 39-64.

Arenas Esteban, J. y Martínez Naranjo, J. (1999): “La explotación de la sal durante la Edad del Hierro en el Sistema Ibérico", en F. Burillo (coord.), IV Simposium sobre los Celtiberos. Economía: 209-212. Zaragoza, Institución Fernando el Católico.

Argilés, V. (2006): “Catálogo de Fuentes y Salinas en la comarca Requena-Utiel". Oleana. Cuadernos de Cultura Comarcal 2: 379-401.

Arias, I. (2005): "La sal: su historia, importancia, aportaciones a la cultura universal", en J. Molina y M. J. Sánchez Fernández (eds.), III Congreso Internacional de Estudios Históricos. El Mediterráneo: la cultura del mar y la sal: 27-32. Santa Pola, Ayuntamiento de Santa Pola.

Battaglini, G. (2005): "La sal en los orígenes de la ciudad de Roma", en J. Molina y M. J. Sánchez Fernández (eds.), III Congreso Internacional de Estudios Históricos. El Mediterráneo: la cultura del mar y la sal: 65-75. Santa Pola, Ayuntamiento de Santa Pola.

Bustos, J. (1993): “Indios y blancos, sal y ganado más allá de la frontera. Patagones 1820-1830". Anuario del Instituto de Estudios Histórico Sociales 8: 27-46.

Carrasco, J. F. y Hueso, K. (2006) "ETNOSAL, un intento de recuperar la memoria salinera de CastillaLa Mancha". Oppidum: cuadernos de investigación, 2: 85-106.
Carrilero, M. (2005): "Sal y comercio costa interior en la prehistoria reciente y protohistoria de la alta Andalucia”, en J. Molina y M. J. Sánchez Fernández (eds.), III Congreso Internacional de Estudios Históricos. El Mediterráneo: la cultura del mar y la sal: 37-55. Santa Pola, Ayuntamiento de Santa Pola.

Castro, J. C. (2006): "La salina romana de O Areal, Vigo (Galice)", J.-C. Hocquet, J.-L. Sarrazin (dirs.), Le Sel de la Baie: histoire, archéologie, ethnologie des sels atlantiques: 105-122. Rennes, Presses Universitaires de Rennes.

Cerdeño, M. L. y Pérez de Inestrosa, L. (1992): “La explotación de sal en época celtibérica en la región de Sigüenza (España)", en Actes du Colloque Intemational du sel: 167-175. Salies-de-Béarn (1992), Salies-de-Béarn, Villa de Salies-de-Béarn.

Corell, J. (1996): Inscripcions romanes del País Valencià. Edeta i el seu territorio. Valencia, Universitat de València.

De Hoz, J. (2002): "La leyenda monetal Ikalesken (MLH A.95)", en Actas del X Congreso nacional de Numismática: 212-219. Albacete (1998), Madrid, Museo Casa de la Moneda.

Fíguls, A. y Weller, O. (2017): "La sal como dinamizador económico en la prehistoria reciente del nordeste peninsular. La Vall Salina de Cardona". Cuaternario y Geomorfología 31 (1-2): 25-44. https:// doi.org/10.17735/cyg.v31i1-2.54683.

García Lenberg, J. (2005): "La utilización de especias en la cocina de la antigua Mesopotamia según la documentación escrita". Isimu. Revista sobre Oriente Próximo y Egipto en la antigüedad 8: 115-126.

García Vargas, E. y Martínez Maganto, J. (2006): “La sal de la Bética. Algunas notas sobre su producción y comercio". Habis 37: 253-274. http://dx.doi. org/10.12795/Habis.2006.i37.19.

García Vargas, E. y Martínez Maganto, J. (2017): “Salines d'évaporation solaire dans l'Empire Romain: témoignages archéologiques d'une activité éphémère", en R. González Villaescusa, K. Schörle, F. Gayet y F. Rechin (eds.), L'exploitation des ressources maritimes de l'Antiquité: 197-212. Antibes, APDCA.

Gil-Mascarell, M. (1977): "Excavaciones en la cuevaritual ibérica de Villargordo del Cabriel (Valencia)", en XIV Congreso Nacional de Arqueología. Congresos Arqueológicos Nacionales: 705-710. Vitoria (1975), Zaragoza, Congresos Arqueológicos Nacionales.

Gómez-Pantoja, J. y Sánchez Moreno, E. (2003): “Antes de la Mesta”, en F. Novoa y L. Elías (coords.), 
Un camino de ida y vuelta: la trashumancia en España: 23-35. Barcelona, Lunwerg.

Gozalbes, E. (2017): "La ceca de Ikalesken y el problema de su localización". Gaceta Numismática 193: 3-19.

Hortelano, J. L. (2007): “Aproximación al estudio de las salinas en el altiplano de Requena: noticias y relaciones de las salinas en el altiplano de RequenaUtiel". Oleana. Cuadernos de Cultura Comarcal 21: 273-284.

Iborra, M. P. (2004): La ganadería y la caza desde el Bronce Final hasta el Ibérico Final en el territorio valenciano. Serie Trabajos Varios, 103. Valencia, Servei d'Investigació Prehistòrica de la Diputació de València.

Iborra, M. P.; Mata, C.; Moreno, A.; Pérez Jordà, G.; Quixal, D. y Vives-Ferrándiz, J. (2010): "Prácticas culinarias y alimentación en asentamientos ibéricos valencianos", en C. Mata, G. Pérez Jordà y J. Vives Ferrándiz (eds.), De la cuina a la taula. IV Reunió d'Economia en el primer mil·lenni a.C. Saguntum-PLAV Extra 9: 100-115. Valencia, Universitat de València.

Ikram, S. (2010): "Mummification". UCLA Encyclopedia of Egyptology, 1(1): 1-5. University of California.

Iranzo, E. (2005): Las salinas continentales en la provincia de Valencia. Aproximación al estudio de un elemento singular del patrimonio rural. Valencia, Departament de Geografia de la Universitat de València.

Iranzo, E. (2006): "Los Espacios Salineros de Interior: El caso de la Comarca Requena-Utiel". Oleana. Cuadernos de Cultura Comarcal 21: 219-248.

Kern, A.; Kowarik, K.; Reschreiter, H. y Rausch, A. W. (2013): El reino de la sal. Alicante, MARQ.

Latorre, I. (2001): "Jaraguas, una breve descripción". El Lebrillo Cultural 15: 7-15.

Lorrio, A. J.; Gómez, P.; Montero, I. y Rovira, S. (1999): "Minería y metalurgia celtibérica", en F. Burillo (coord.), IV Simposium sobre los Celtiberos. Economía: 161-180. Daroca (1997), Zaragoza, Institución Fernando el Católico.

Lorrio, A. J.; Moneo, T.; Moya, F.; Pernas, S. y Sánchez De Prado, Ma . D. (2006): "La Cueva Santa del Cabriel (Mira, Cuenca): Lugar de culto antiguo y ermita cristiana". Complutum, 17: 45-80.

Lozano, L. (2006): "El centro artesanal iberorromano de La Maralaga (Sinarcas, Valencia)". SaguntumPLAV 38: 133-148. https://doi.org/10.7203/SAGVNTVM.38.1044.
Luján, E. (2003): "En torno a la identificación de la ceca Ikale(n)sken (MLH A.95)". Palaeohispanica 3: 129-135.

Machause, S. y Quixal, D. (2019): “Cuevas rituales ibéricas en el territorio de Kelin (ss. V-III a.C.)". Complutum 29(1): 115-134. https://doi.org/10.5209/ CMPL.62398.

Martínez Maganto, J. (2005): "La sal en la Antigüedad: aproximación a las técnicas de explotación y comercialización. Los salsamenta”, en J. Molina y M. J. Sánchez Fernández (eds.), III Congreso Internacional de Estudios Históricos. El Mediterráneo: la cultura del mar y la sal: 113-128. Santa Pola, Ayuntamiento de Santa Pola.

Martínez Maganto, J. (2012): “La producción feniciopúnica de sal en el contexto del Mediterráneo occidental desde una perspectiva diacrónica", en B. Costa y J. Hernández (eds.), Sal, pesca y salazones fenicios en Occidente: 9-32. Eivissa, Museu Arqueològic d'Eivissa i Formentera.

Martínez Valle, A. (1995): "En torno a la localización de la ceca de Ikalesken", en Actas IX Congreso Nacional de Numismática: 59-66. Elche, Ayuntamiento de Elche.

Martínez Valle, A. y Castellano, J. J. (1995): “Conjunto de fusayolas ibéricas de dos cuevas santuario de la comarca de Requena Utiel", en Actas del XXIII Congreso Nacional de Arqueología 1: 525-536. Elche, Ayuntamiento de Elche.

Martínez Valle, A. y Castellano, J. J. (2001): "Los hornos ibéricos de las Casillas del Cura (Venta del Moro, Valencia)", en A. J. Lorrio (coord.), Los Íberos en la Comarca de Requena-Utiel, 135-150. Madrid, Universidad de Alicante.

Mata, C. (1991): Los Villares (Caudete de las Fuentes): origen y evolución de la cultura ibérica. Serie Trabajos Varios, 88. Valencia, Servei d'Investigació Prehistòrica de la Diputació de València.

Mata, C. (2001): "Límites y fronteras en "Edetania". Archivo de Prehistoria Levantina 24: 243-272.

Mata, C. (2019): De Kelin a Los Villares (Caudete de las Fuentes, Valencia). Nacimiento y decadencia de una ciudad ibera. Serie Trabajos Varios, 122. Valencia, Servei d'Investigació Prehistòrica de la Diputació de València.

Mata, C.; Bonet, H.; Collado, E.; Fuentes, M.; Izquierdo, I.; Marlasca, R.; Moreno, A.; Pascual, J. L.; Quesada, F.; Quixal, D.; Ripollès, P. P.; Sanchis, A.; Soria, L. y Tormo, C. (2014): Fauna Ibérica. De lo real a lo imaginario (II). Serie Trabajos Varios, 
117. Valencia, Servei d'Investigació Prehistòrica de la Diputació de València.

Mata, C.; Duarte, F.; Garibo, J.; Valor, J. y Vidal, X. (2000): "Las cerámicas ibéricas como objeto de intercambio", en C. Mata y G. Pérez Jordà (eds.), Ibers. Agricultors, artesans i comerciants. III Reunió sobre Economia en el Món Ibèric. SaguntumPLAV Extra 3: 389-397. Valencia, Universitat de València.

Mata, C.; Moreno, A. y Ferrer, M. A. (2009a): "Iron, Fuel and Slags: Reconstructing the Ironworking process in the Iberian Iron Age (Valencian Region)". Pyrenae 40 (2): 105-127.

Mata, C.; Moreno, A.; Pérez Jordà, G.; Quixal, D. y Vives-Ferrándiz, J. (2009b): “Casas y cosas del campo: hábitat agrícola y estructura social en los territorios de Edeta y Kelin (siglos V-III A.N.E.)", en M. C. Belarte (ed.), Espai domèstic i l'organització de la societat a la protohistòria de la Mediterrània occidental (1er mil-lenni a C). Serie Arqueo Mediterrània 11: 143-152. Barcelona, Universitat de Barcelona; Institut Català d'Arqueologia Clàssica.

Mederos, A. y Ruiz Cabrero, L. (2000-2001): “Trashumancia, sal y comercio fenicio en las cuencas de los ríos Vinalopó y Bajo Segura (Alicante)". Lucentum XIX-XX: 83-94. https://doi.org/10.14198/LVCENTVM2000-2001.19-20.06.

Molina, J. (2005): "La cetaria de La Picola y la evolución del Portus Ilicitanus (Santa Pola, Alicante)", en J. Molina y M. J. Sánchez Fernández (eds.), III Congreso Internacional de Estudios Históricos. El Mediterráneo: la cultura del mar y la sal: 95-102. Santa Pola, Ayuntamiento de Santa Pola.

Moreno, A. (2011): Cuando el paisaje se convierte en territorio: aproximación al proceso de territorialización íbero en La Plana d'Utiel, València (ss. VI-II ane). BAR International Series 2298. Oxford, Archaeopress.

Moreno, A. y Quixal, D. (2009): "El territorio inmediato de Kelin en época ibérica (siglos IV-III a.C.). Estrategias productivas y poblacionales". Saguntum-PLAV 41: 109-118.

Morère, N. (1994): "La sal en la Península Ibérica. Los testimonios literarios antiguos". Hispania Antiqua, XVIII: 235-250.

Multhauf, R. P. (1985): El legado de Neptuno. México, Fondo de Cultura Económica.

Nenquin, J. (1961): Salt. A study in Economic Prehistory. Dissertationes Archaeologicae Gandenses VI. Brujas, De Tempel.
Nicholson, P. (2009): "Faience technology". UCLA Encyclopedia of Egyptology, 1(1): 1-11. University of California.

Palomero, S. (1987): Las vías romanas en la actual provincia de Cuenca. Cuenca, Diputación Provincial.

Panadero, A. (2001): "Las Salinas de Jaraguas". El Lebrillo Cultural 15: 17-18.

Pancorbo, A. (2019): "Resultats preliminars de la intervenció arqueológica duta a terme al camp de fútbol de Cardona (2015-2016): El jaciment del Campet de la Sal". IV Jornades d'Arqueologia de la Catalunya Central: 192-201. Solsona (2016), Solsona, Generalitat de Catalunya.

Pérez-Rojas, M. (1978): Estudio estructural de las instituciones civiles a través de la epigrafía hispánica. Tesis doctoral inédita, Universidad Complutense de Madrid.

Piqueras, J. (1997): La Meseta de Requena-Utiel. Requena, Centro de Estudios Requenenses.

Piqueras, J. y Sanchis, M. C. (1991): "La trashumancia ibérico-valenciana en la Edad Moderna". Cuadernos de Geografía 49: 197-212.

Plácido, D. (2005): “Los viajes de los héroes, los riesgos del mar y los usos de la sal en el extremo occidente", en J. Molina y M. J. Sánchez Fernández (eds.), III Congreso Internacional de Estudios Históricos. El Mediterráneo: la cultura del mar y la sal: 57-63. Santa Pola, Ayuntamiento de Santa Pola.

Pruneda, P. (1869): Crónica de la Provincia de Cuenca. Madrid, Editores Rubio, Grilo y Vitturi.

Quesada, F. y García-Bellido, M.P. (1995): "Sobre la localización de ikale(n)sken y la iconografía de sus monedas", en M. P. García-Bellido y R. M. Sobral (eds.), La moneda hispánica. Ciudad y territorio, Anejos de Archivo Español de Arqueología 14: 6573. Madrid, CSIC.

Quixal, D. (2012): “El valle del Magro como vía de comunicación en época ibérica (siglos VI-I a.C.)". Archivo de Prehistoria Levantina XXIX: 187-208.

Quixal, D. (2015): La Meseta de Requena-Utiel (Valencia) entre los siglos II a.C. y II d.C. La Romanización del territorio ibérico de Kelin. Serie Trabajos Varios, 118. Valencia, Servei d'Investigació Prehistòrica de la Diputació de València.

Quixal, D. (2018): "Flora y fauna en la Meseta de Requena-Utiel en tiempos de los iberos". Oleana. Cuadernos de Cultura Comarcal 33: 461-486.

Quixal, D. (2020): "Mining and metallurgy in the Iberian territory of Kelin ( $4^{\text {th }}-1^{\text {st }}$ centuries BC)", en M. C. Belarte; M. C. Rovira y J. Sanmartí (eds.), Iron 
metallurgy and the formation of complex societies in the Western Mediterranean (1 $1^{\text {st }}$ millennium $B C$ ). Serie Arqueo Mediterrània 15: 161-168. Barcelona, Universitat de Barcelona; Institut Català d'Arqueologia Clàssica.

Quixal, D. y Moreno, A. (2011): "Vadocañas y los vados sobre El Cabriel en época ibérica". El Lebrillo Cultural 28: 15-20.

Ripollès, P.P. (1999): "De nuevo sobre la localización de $I K A L E(N) S K E N$ ", en M. A. Valero (coord.), Las Jornadas de Arqueología Ibérica en Castilla-La Mancha: 145-168. Toledo, Junta de Comunidades de Castilla-La Mancha.

Ripollès, P. P.; Collado, E. y Delegido, C. (2013): “Los hallazgos monetales y la plata en bruto de La Carència”, en R. Albiach (coord.), L'oppidum de la Carència de Torís i el seu territori. Serie Trabajos Varios, 116: 153-230. Valencia, Servei d'Investigació Prehistòrica de la Diputació de València.

Sandison, A. T. (1963): "The use of natron in mummification in Ancient Egypt". Journal of Near Eastern Studies 22(4): 259-267.

Sanz Gamo, R. (1997): Cultura ibérica y romanización en tierras de Albacete: los siglos de transición. Albacete, Instituto de Estudios Albacetenses.

Sillières, P. (1977): “El Camino de Aníbal, itinéraire des gobeletes de Vicarello de Castulo à Saetabis", Mélanges de la Casa de Velázquez 13 (2): 31-83.

Soria, L.; García Huerta, R.; Rodríguez, D. y Morales, F. J. (2016): "Poblamiento rural de época ibérica en el área central de La Manchuela (Albacete)", en B. Gamo y R. Sanz Gamo (coords.), Actas de la I Reunión de Arqueología de Albacete: 51-70. Albacete, Diputación de Albacete.

Terán, J. (2011): "La producción de sal en la Prehistoria de la Península Ibérica: estado de la cuestión”. Arqueología y Territorio 8: 71-84.

Terán, J. (2014): "La sal, el oro blanco de las sociedades preindustriales: uso y técnicas de obtención en la prehistoria peninsular", en J. M. López Ballesta (coord.): Uso y gestión de recursos naturales en medios semiáridos del ámbito mediterráneo: II Encuentros Internacionales del Mediterráneo: 195 208. Mazarrón, Ayuntamiento de Mazarrón.

Terán, J. (2017a): La explotación de la sal en el sistema ibérico central durante el I milenio a.C. Tesis doctoral, Universidad de Zaragoza: https://zaguan. unizar.es/record/61512? $\ln =$ es (Consultada el 0202-2019).

Terán, J. (2017b): “Sal, monedas, vías y fuentes.: La localización de Egelasta: un problema por resolver", en L. J. García Pulido y L. Arboledas (eds.): Presente y futuro d-e los paisajes mineros del pasado: Estudios sobre minería, metalurgia y poblamiento: 355-365. Granada, Universidad de Granada.

Untermann, J. (1975): Monumenta Linguarum Hispanicarum. Wiesbaden, Dr. Ludwig Reichert Verlag.

Untermann, J. (1992): "Etnónimos y lenguas de la Hispania antigua", en M. Almagro Gorbea y G. Ruiz Zapatero (eds.), Paleoetnología de la Penísula Ibérica. Reflexiones y perspectivas de futuro: 22-43. Madrid, Universidad Complutense de Madrid.

Valero, M.A. (1995): "Una inscripción funeraria procedente de Iniesta”, Saguntum-PLAV 28: 283-286.

Valero, M.A. (2010): "La necrópolis ibérica de la Punta del Barrionuevo, Iniesta, Cuenca: avance sobre las últimas investigaciones", en A. Madrigal y M. R. Perlines (coords.), Actas de las II Jornadas de Arqueología de Castilla-La Mancha vol. 2: 1010-1045. Toledo (2007), Toledo, Diputación Provincial.

Valiente, S.; Giles Pacheco, F.; Gutiérrez, J. M.; Carrascal, J. M.; Giles Guzmán, F. y Reinoso, M. C. (2017): "Sistemas de extracción, explotación y comercio de sal continental en la Península Ibérica desde la Protohistoria a época romana". De Re Metallica 28: 35-46.

Villaronga, L. (1962): Los denarios con leyenda Icalkusken. Barcelona, Asociación Numismática Española.

Villaronga, L. (1980): "Sistematització de les monedes de bronde d'Ikalkusken, Kelin i Urkesken". Acta Numismàtica 10: 41-60.

Villaronga, L. (1988): Els denaris ibèrics d'Ikalkusken. Estudis Numismàtics Valencians 3, Valencia, Generalitat Valenciana.

Weller, O. (2004): "Los orígenes de la producción de sal: evidencias, funciones y valor en el Neolítico europeo", Pyrenae 35: 93-116.

Weller, O. (2015): "First salt making in Europe: an overview from Neolithic times". Documenta Praehistorica XLII: 185-196. https://doi.org/10.4312/dp.42.12.

Yeves, A. (2000): Aspectos geológicos de la Comarca de Requena-Utiel. Requena, Centro de Estudios Requenenses. 